\title{
ZNO Nanoparticles as a Model for Removal of Pharmaceutical Compounds (Vitamin B12)in the Presence of UVA Light
}

\author{
Aseel M. Ajobree, Ali T. Bader, Ayad F. Alkaim, Falah H. Hussein
}

\begin{abstract}
The photocatalytic degradation of an aqueous solution of Vitamin B12 drug has studied under different conditions in the presence of $\mathrm{ZnO}$ nanoparticles suspension. The effect of various parameters such as mass of $\mathrm{ZnO}$, Vitamin $\mathrm{B12}$ drug concentration and study Removal of a real sample (mixture of pharmaceuticals compounds) by using ZnO. Results showed that, the photo catalytic degradation process was high at the beginning and then decreased with time. The explained the photo catalytic degradation efficiency, which was increased by increasing catalyst loading from 0.05 to $0.2 \mathrm{~g}$. The degradation efficiency decreased with the increase in catalyst loading. Results also showed that the rate of photo catalytic degradation was increased with decreasing Vitamin B12 drug concentration.
\end{abstract}

Keywords : Photocatalytic, Pharmaceutical, Vitamin B12 drug, $\mathrm{ZnO}$ nanoparticles.

\section{INTRODUCTION}

Pharmaceuticals are frequently detected in treated wastewater arising from sewage treatment plants, from which they are not completely removed $[1,2]$. Moreover, recent studies have reported the presence of traces or ultra-traces (ng L-1) of Pharmaceuticals in drinking water [3, 4]. Many of these compounds are also suspected to have adverse impact on humans and wild life $[5,6]$.Huge types of drug uses led to pollute the surface water and groundwater., there are different methods used for water treatment in our previous work[7-10]. Advanced oxide processes (AOP) method can be used to wastewater treatment[11]. It has been ability to convert the pollutants into the harmless materials. hydroxyl radicals $\left({ }^{\circ} \mathrm{OH}\right)$, this reactive radical capable of mineralizing organic pollutants[12]ZnO is an important material for various environmental and technical applications, e.g., photocatalysis, dye-sensitized solar cells, photovoltaic and self-cleaning materials.[13-15] It exists commonly in nature in three phases: anatase, brookite and rutile. Under ambient conditions microcrystalline rutile is thermodynamically stable relative to microcrystallineanatase and brookite. However, the phase transitions between the three phases are dependent on many factors such as particle size, $\mathrm{pH}$, surface energy, and solution chemistry.[16, 17] For

Revised Manuscript Received on July 22, 2019.

Aseel M. Ajobree, Ali T. Bader, Ayad F. Alkaim, Falah H. Hussein College of science for women-Chemistry Department/ University of Babylon -Iraq Almustaqbal University College, HILLA, IRAQ instance, if the particle sizes of the three phases are equal, anatase is the most thermodynamically stable phase for crystal sizes below ca. $11 \mathrm{~nm}$, brookite is most stable for crystal sizes between ca. 11 and $35 \mathrm{~nm}$, and rutile is most stable for crystal sizes exceeding 35 $\mathrm{nm}[18]$.

\section{EXPERIMENTAL PART}

\section{A. Materials}

Commercial ZnOnanoparticles powder were purchased from (sigma-Aldrich, Germany) , ( Methylcobalamin) Vitamin B12 drug was supported by Hila Company of samara factory drug/ Iraq. All chemicals used in this study were analytical grade and used directly without further purification. Vitamin B12 chemical formula:C63H88CoN14O14P, MW: $1355.388 \mathrm{~g} \bullet \mathrm{mol}-1$, $\lambda \max 530 \mathrm{~nm}]$ The chemical structures are shown in (Fig. 1).

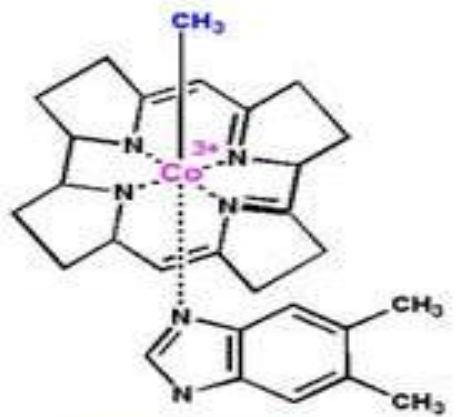

Figure: 1 Chemical structure of ( Methylcobalamin) Vitamin B12 drug

\section{B. Preparation standard solutions}

Freshly prepared aqueous solution of the pure drugs .vitamin B12to prepare stock solution $(1000 \mathrm{mg} / \mathrm{L})$. by dissolving $1 \mathrm{gm}$ of vitamin B12 drug in distilled water the solution was made up to $1000 \mathrm{~mL}$ with distilled water. Concentrations of drug were determined by finding out the absorbance at the characteristic wavelength using a double beam UV/Vis spectrophotometer (UV-Visible spectrophotometer, Shimadzu 1650). Calibration curves were plotted between absorbance and concentration of the drug solution. 


\section{Photocatalytic experiments}

The photo catalytic activity of the $\mathrm{ZnO}$ nanoparticles photo catalyst was evaluated by the degradation of vitamin B12 drug wastewater. All experiments were carried out in a photo-reaction vessel, with $200 \mathrm{ml}$ of total capacity. A $125 \mathrm{~W}$ high-pressure mercury lamp with the strongest emission at $530 \mathrm{~nm}$ was used as light source. The beakers were put under the ultraviolet light maintaining the distance between the light source and the surface of the solution controlled by using UVA-meter (Dr. Honle/Germany).Prior to each test, the lamp was turned on and warm up for about $15 \mathrm{~min}$ in order to get a constant output. Batch tests were performed as the following procedure, $0.2 \mathrm{~g} \mathrm{ZnOphoto}$ catalyst was added into $200 \mathrm{~mL}$ drug solutions, the mixture was stirred in dark for $15 \mathrm{~min}$ to allow the physical adsorption of drug molecules on catalyst particles reaching the equilibrium.

Subsequently, the mixture was poured into the photo reactor and began the photo catalytic degradation tests. The reaction solution was mixed by an air diffuser, which was placed at the bottom of the reactor to uniformly disperse air into the solution with a flow rate of $0.1 \mathrm{ml} / \mathrm{min}$.

Samples were collected at regular intervals and were immediately centrifuged to remove particles for analysis. The concentration of drug was determined by measuring the absorption intensity at its maximum absorbance wavelength of $\lambda=530 \mathrm{~nm}$, by using a UV-Vis spectrophotometer (1650 Shimadzu, Japan) with a $1 \mathrm{~cm}$ path length spectrometric quartz cell, and then calculated from calibration curve.

Effect of various operational parameters such as amount of catalyst $\left(0.5-2.0 \mathrm{~g} \mathrm{~L}^{-1}\right)$, and concentration of drug (10-50 $\left.\mathrm{mgL}^{-1}\right)$ on the photo degradation efficiency was studied. The percentage removal of photo catalytic degradation of Vitamin B12 drug and apparent first order rate constant were calculated using the following relationships

$$
\begin{aligned}
& \operatorname{PDE}(\%)=100 \times\left(\mathrm{C}_{0}-\mathrm{C}_{\mathrm{t}}\right) / \mathrm{C}_{0} \\
& \left(\frac{\mathbf{C}_{\mathrm{t}}}{\mathbf{C}_{\mathbf{0}}}\right)=\mathbf{e}^{-\mathrm{kt}}
\end{aligned}
$$

Where, $C_{0}$ and $C_{t}$ are the initial and photolyzed concentration $(\mathrm{mg} / \mathrm{L})$, respectively, PDE (photo catalytic degradation efficiency), $\mathrm{t}$ is time of irradiation (min.) and $k$ is the apparent first order rate constant $\left(\mathrm{min}^{-1}\right)$.

\section{RESULT AND DESICCATION}

\section{Effect of mass dosage}

The influence of the photo catalyst concentration (0.5 $2 \mathrm{gL}^{-1}$ ) on the photo catalyticdegradation of Vitamin B12 drug was investigated at an initial Vitamin B12 drug concentration of 10ppm, lightintensity (1.4 $\mathrm{mW} / \mathrm{cm} 2$, flow rate of $\mathrm{O} 2\left(5 \mathrm{~mL} \cdot \mathrm{min}^{-1}\right)$ and buffer concentration of thesuspension $\mathrm{pH}$ 6.[19]

In the region less than $2 \mathrm{gL}^{-1}$, when the mass dosage were increased, the rate of degradation was increased because the number of active sites increased. In the region between $0.5-2 \mathrm{gL}^{-1}$, shows an approximately plateau curve which indicates the numbers ofactive sites have an equilibrium between the numbers of photon induced that absorbed by the catalyst and a particle of drug adsorbed[20-22].Fig.2 represents the percent degradation of Vitamin B12 drug against the different amount of catalyst. This shows that the percent degradation of modified catalysts increase with increase in the amount of catalyst from0.5 - $2 \mathrm{gL}^{-1}$ and above this limit there is not much change. [20-22]. This indicated that the active site provided for the adsorption of substrate on the catalyst surface is limited to catalyst amount of $1.5 \mathrm{gL}^{-1}$ and after that low change in the degradation. At higher dosage the vacant sites are consumed by the intermediate products obtained during the reactions which retard further degradation of the substrate. Hence the percent degradation decreased or retained without a noticeable change [23-27].

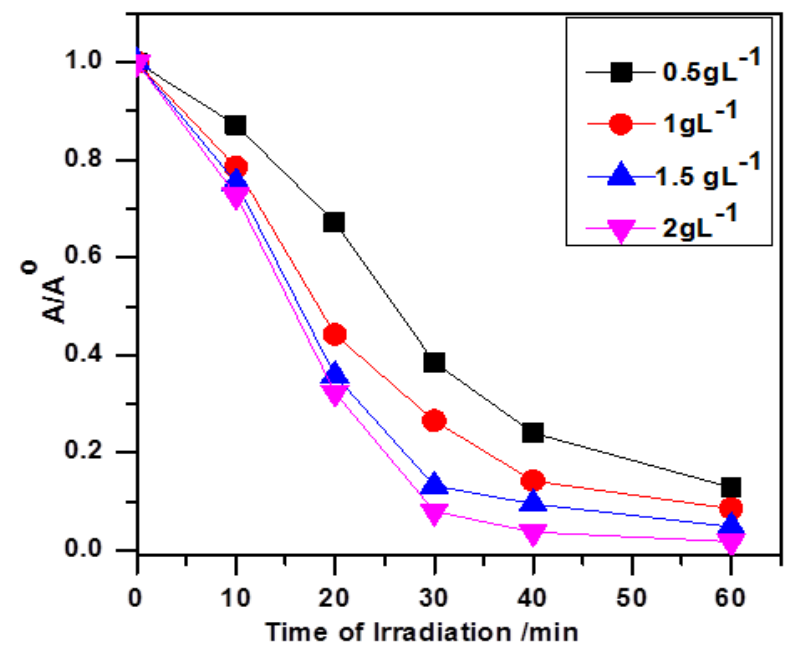

Figure.2.The effect mass of ZnOon Photocatalytic degradation of VitaminB12 drugExperimental Conditions: initial concentration 10ppm, Temp. $25^{\circ} \mathrm{C}$, and L.I. $1.4 \mathrm{~mW} . \mathrm{cm}^{-2}$.

\section{Removal of a real sample (mixture of} pharmaceuticals compounds) by using $\mathrm{ZnO}$

A real sample $200 \mathrm{ml}$ of pharmaceutical pollutants with a refry concentration were using in this study, then added beakers in the presence of $2 \mathrm{gL}^{-1}$ from $\mathrm{ZnO}$, after that the mixture the beaker was put under the ultraviolet light maintaining the

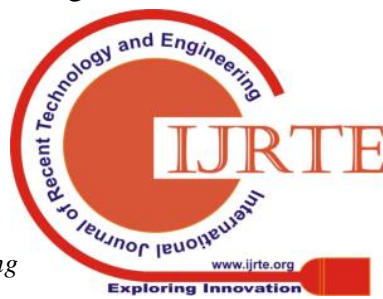


distance between the light source and the surface of the solution controlled by using UVA-meter (Dr. Honle/Germany)for $1 \mathrm{hr}$, after that the supernatant were separated by centrifuge and measured the remaining concentration by using UV-Visible spectrophotometer at a chosen wavelength at $530 \mathrm{~nm}$ show in fig. 3 and found when time increase the absorption decrease and gave higher percentage removal[28].

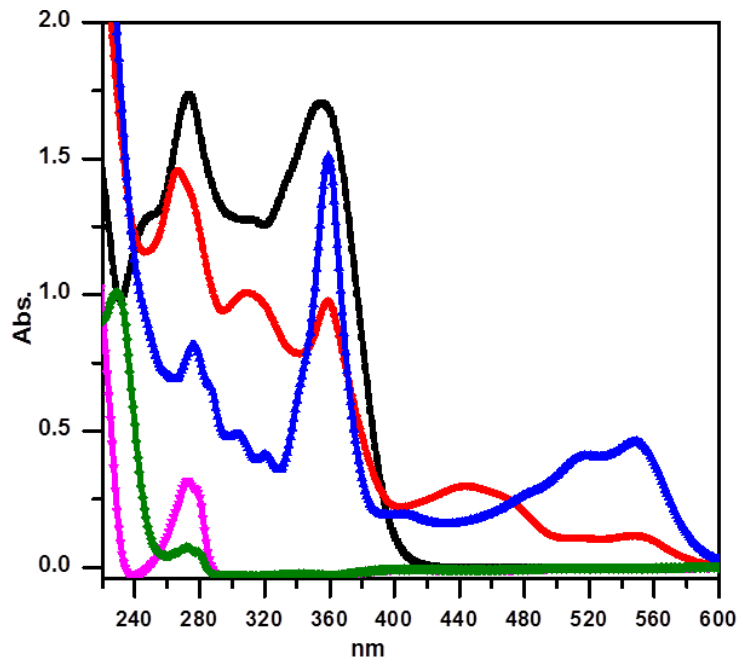

Figure 3: Effect Removal of a real sample (mixture of pharmaceuticals compounds) by using $\mathrm{ZnO}$. Experimental Conditions: mass amount 2 g. $\mathrm{L}^{-1}$, initial concentration 10ppm, Temp. $25{ }^{\circ} \mathrm{C}$, and L.I. 1.4 $\mathrm{mW} . \mathrm{cm}^{-2}$.

The Effect of initial Vitamin B12 drug concentration on photo catalytic degradation processes :

The effect of change initial ( $10-50 \mathrm{mg} / \mathrm{L})$ on Photocatalytic degradation process of Vitamin B12drug was studied using $2 \mathrm{gL}^{-1}$, the light intensity equal to1.4 $\mathrm{mW} / \mathrm{cm}^{2}$, and temperature equal to $298 \mathrm{~K}$. The results are plotted in Fig.4 It has been observed that the rate of Photocatalytic degradation gradually decreases with the increasing of initial Vitamin B12 drug concentration. This behavior could be explained, the concentration $10 \mathrm{ppm}$ was the optimum concentration to cover the largest area of the $\mathrm{ZnO}$ particles, therefore absorbed maximum exciting photons to generate higher concentration of the activated $\mathrm{ZnO}$ semiconductor. Another reason for this behavior is the strong absorption of light by the Vitamin B12 drug the sample which contain high concentration that 10ppm, Vitamin B12 drug on $2 \mathrm{~g} / \mathrm{L}^{-1}$ of $\mathrm{ZnO}$. The excess of Vitamin B12 drug prevent the penetration of light through the successive layers of Vitamin B12 drug on the $\mathrm{ZnO}$ surface is weak to generate the required excited state of the Vitamin B12 drug on $\mathrm{ZnO}[29][12,30]$. The concentration of Vitamin B12drug 10ppm gives the optimum Photocatalytic degradation efficiency which is equal to $100 \%$. The results of the change in percentage Photocatalytic degradation efficiency (E \%) with concentration of Vitamin B12drug plotted in Fig.5.

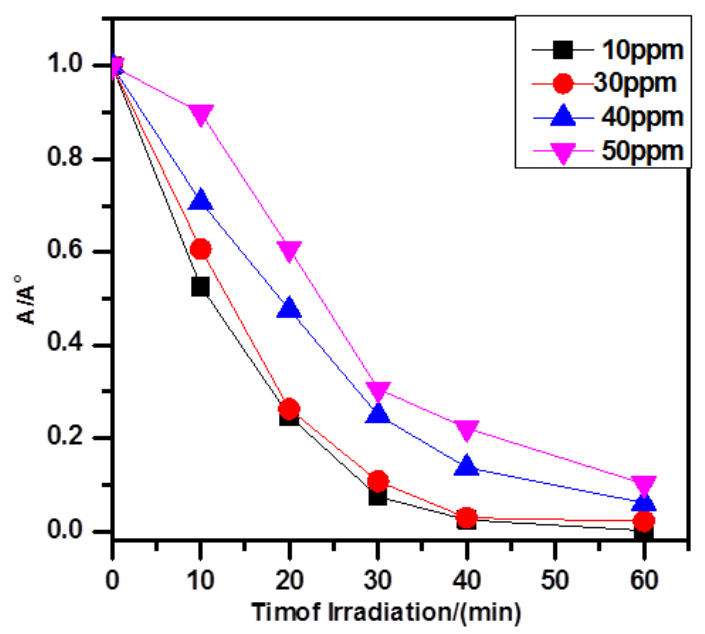

Figure 4: Photo catalytic degradation of B12 drug at different initial concentration. Experimental Conditions: mass amount 2 g. $\mathrm{L}^{-1}$, Temp. $25^{\circ} \mathrm{C}$, and L.I. $1.4 \mathrm{~mW} . \mathrm{cm}^{-2}$.

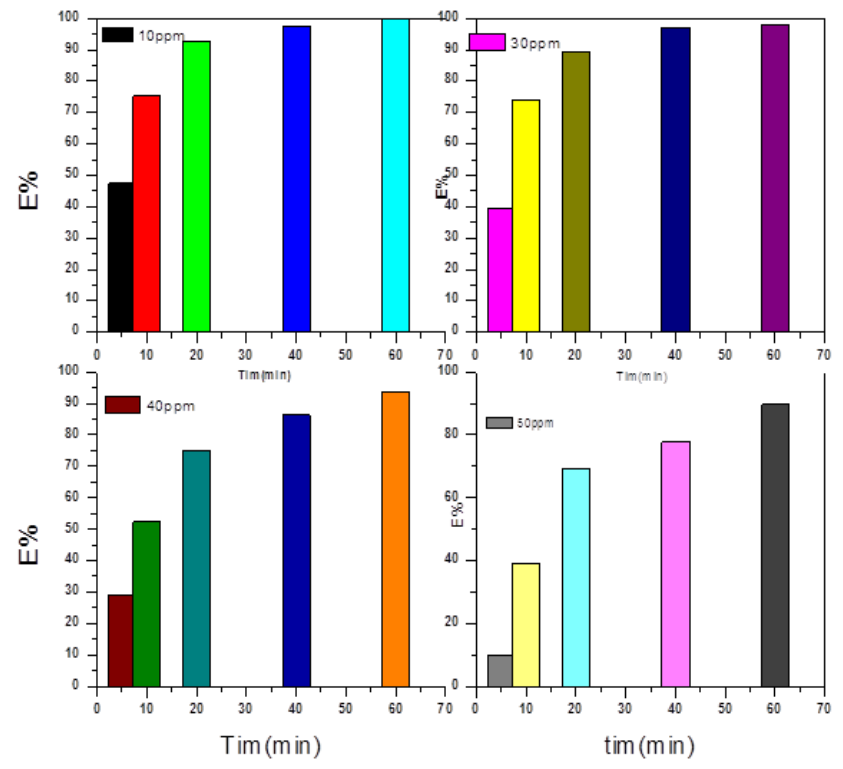

Figure 5: percent removal B12 drug at different initial concentration. Experimental Conditions: mass amount 2 g.L ${ }^{-1}$, Temp. $25^{\circ} \mathrm{C}$, and L.I. $1.4 \mathrm{~mW} . \mathrm{cm}^{-2}$. 


\section{CONCLUSION}

The obtained results show that Vitamin B12 drug can be easily degraded by a $\mathrm{ZnOassisted} \mathrm{process} \mathrm{in} \mathrm{aqueous}$ dispersions under UV irradiation. The photo degradation of the drug follows first order kinetics and parameters like the $\mathrm{ZnO}$ concentration, initial drug concentration affect the photo degradation effect. The results indicated that the catalyst loading, light intensity and the initial drug concentration affected the degradation efficiency of $\mathrm{ZnO}$ powders obviously. We learned that the photo degradation efficiency is enhanced with the increase of catalyst loading and the reverse effect is obtained with the increase of initial drug concentration in our experiments. The photo catalytic decomposition of Vitamin B12 drug was most efficient in the solution at lower initial concentration.

\section{REFERENCES}

1. Aseel M. Aljeboree, A.N.A., Adsorption of Pharmaceuticals as emerging contaminants from aqueous solutions on to friendly surfaces such as activated carbon: A review J. Pharm. Sci. \& Res. , 2018. 10(9): p. 2252-2257

2. J.L. Tambosi, L.Y.Y., H.J.J.R. de Fátima Peralta Muniz Moreira, H.F. Schröder, Recent research data on the removal of pharmaceuticals from sewage treatment plants (STP). Quim Nova, 2010. 33: p. 411-420.

3. Aseel Musthaq Aljeboree , A.N.A., Colorimetric Determination of phenylephrine hydrochloride drug Using 4-Aminoantipyrine: Stability and higher sensitivity J. Pharm. Sci. \& Res., 2018 10(7): p. 1774-1779

4. Jones, O.A., J.N. Lester, and N. Voulvoulis, Pharmaceuticals: a threat to drinking water? Trends in Biotechnology, 2005. 23(4): p. 163-167.

5. Aseel M. Aljeboree , A.S.A., Removal of Pharmaceutical (Paracetamol) by using CNT/ TiO2 Nanoparticles. Journal of Global Pharma Technology, 2019. 11 ( 01 ): p. 199-205.

6. Stackelberg, P.E., et al., Persistence of pharmaceutical compounds and other organic wastewater contaminants in a conventional drinking-water-treatment plant. Science of The Total Environment, 2004. 329(1): p. 99-113.

7. A.F. ALKAIM1, A.M.A.N.A.A., S.J. BAQIR2 , F.H. HUSSEIN and A.J. LILO2, Effect of $\mathrm{pH}$ on Adsorption and Photocatalytic Degradation Efficiency of Different Catalysts on Removal of Methylene Blu.

8. Aljeboree, A.M., A. N. Alshirifi, et al. , "Kinetics and equilibrium study for the adsorption of textile dyes on coconut shell activated carbon.Arabian Journal ofChemistry, 2012. 10: p. S3381-S3393.

9. Alkaim AF, A.A., Alrazaq NA, Baqir S.J, Hussein F.H and Lilo AJ, Effect of $\mathrm{pH}$ on Adsorption and Photocatalytic Degradation Efficiency of Different Catalysts on Removal of Methylene Blue. Asian Journal of Chemistry, , 2014. 24(26): p. 8445-8448.

10. AM, A., Adsorption of crystal violet dye by Fugas Sawdust from aqueous solution. International Journal of ChemTech Research. 9(3): p. 412-423.

11. Abdulrazzak, F.H., Enhance photocatalytic Activity of $\mathrm{TiO} 2$ by Carbon Nanotubes.International Journal of ChemTech Research, 2016. 9(3): p. 431-443

12. AF Alkaim, T.K., FH Hussein, R Dillert, DW Bahnemann, Solvent-free hydrothermal synthesis of anatase $\mathrm{TiO} 2$ nanoparticles with enhanced photocatalytic hydrogen production activity. Applied Catalysis A: General 2013. 466 p. 32-37.

13. Tarek A. Kandiel, L.R., Ayad Alkaim and Detlef Bahnemann, Brookite versus anatase $\mathrm{TiO} 2$ photocatalysts: phase transformations and photocatalytic activities $\nmid$. Photochemical \& Photobiological Sciences, 2013. 12: p. 602.

14. M. R. Hoffmann, S.T.M., W. Y. Choi and, E.a.o.s. D. W. Bahnemann, and C.R. photocatalysis, 1995, 95, 69-96., Environmental applications of semiconductor photocatalysis Chem. Rev, 1995. 95: p. 69-96.

15. K. Hashimoto, H.I.a.A.F., TiO2 photocatalysis:a historical overview and future prospects. J. Appl.Phys., 2005. 44: p. 8269-8285.
16. M. P. Finnegan, H.Z.Z.a.J.F.B., Phase stability and transformation in titania nanoparticles in aqueous solutions dominated by surface energy. J. Phys.Chem. C 2007. 111.: p. 1962-1968.

17. T. A. Kandiel, R.D.a.D.B., Titanium dioxide nanoparticles and nanostructures. Curr. Inorg.Chem., 2012. 2: p. 94-114.

18. Banfield, H.Z.Z.a.J.F., Understanding polymorphic phase transformation behavior during growth of nanocrystalline aggregates: insights from TiO2. J. Phys. Chem. B,, 2000. 104: p. 3481-3487.

19. HUSSEIN, A.F.A.a.F.H., PHOTOCATALYTIC DEGRADATION OF EDTA BY USING TiO2 SUSPENSION.Int. J. Chem. Sci., 2012. 10(1): p. 586-598.

20. H. Wang, C. Xie, W. Zhang, S. Cai, Z. Yang, and Y. Gui, Comparison of dye degradation efficiency using $\mathrm{ZnO}$ powders with various size scales. J. Hazard Mater., 2007. 141(3): p. 645-652.

21. J. Kaur, and S. Singhal, Heterogeneous photocatalytic degradation of rose bengal: Effectof operational parameters. Physica B, 2014. 450: p. 49-53.

22. M. S. Mashkour, A. F. Alkaim, L. M. Ahmed, and F. H. Hussein, Zinc oxide assisted photocatalytic decolorization of reactive red 2 dye. Int. J. Chem. Sc., 2011. 9(3): p. 969-979.

23. M., G.M.S.T.O.-C.A.M.F.P.E.M.P.P.M.S.Q., J., Chemosphere 1999. 39: p. 781

24. G., C.F.X.Y.Z.J.L., Chemosphere 2000. 44: p. 1159.

25. I., P.I.A., J. Chem. Technol. Biotechnol., 1999. 74 p. 349.

26. H., H.L.E.P.A.H.M.K.E.E.C.G.J., Appl. Catal. B: Environ., 2002. 39 p. 75.

27. T. Sauer, G. C. Neto, H.J. José, and R.F. Moreira, Kinetics of photocatalytic degradation of reactive dyes in a $\mathrm{TiO} 2$ slurry reactor. J. Photochem. Photobiol. A, 2002. 149: p. 147-154.

28. Aseel M. Aljeboree, H.Y.A.-G., Mohammed H. Said and Ayad F. Alkaim, THE EFFECT OF DIFFERENT PARAMETERS ON THE REMOVAL OF VITAMIN B12 DRUG (AS A MODEL BIOCHEMICAL POLLUTANTS) BY AC/ CLAY.Biochem. Cell. Arch. , 2019. 19(1): p. 000-000.

29. Miao J, J.Z., Lu HB, Habibi D and Zhang L, , Heterogeneous photocatalytic degradation of mordant black 11 with $\mathrm{ZnO}$ nanoparticles under UV-Vis light. Journal of the Taiwan Institute of Chemical Engineers, 2014. 45: p. 1636-1641

30. Aseel M. Aljeboree, A.F.A., Ali loay2, hanadi $m$ algburi, Photocatalytic Degradation of Textile Dye Cristal Violet Wastewater using Zinc Oxide as a Model of Pharmaceutical Threat Reductions. Journal of Global Pharma Technology, 2019. 11(3): p. 138-143. 